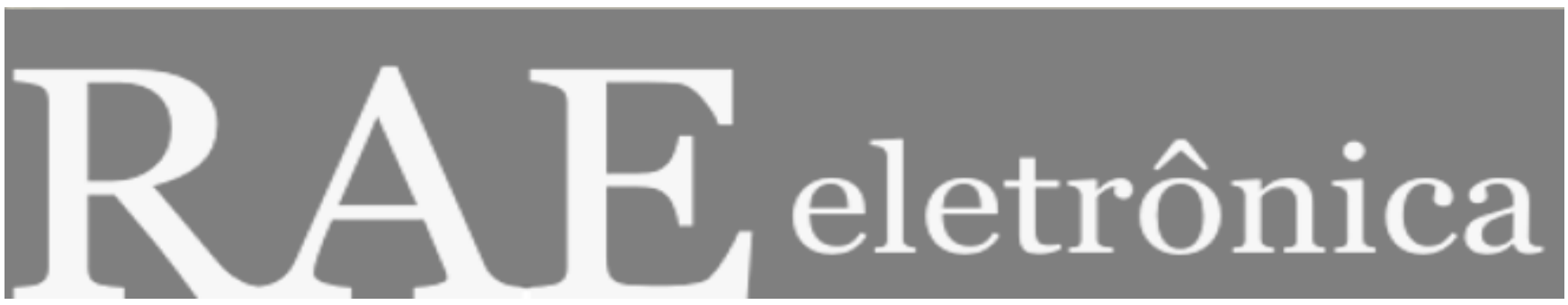

\title{
CAPITAL HUMANO E TI GERANDO VANTAGEM COMPETITIVA
}

Por:

Marcelo Marques

Sylvio Lazzarini Neto

RAE-eletrônica, Volume 1, Número 2, jul-dez/2002.

http://www.rae.com.br/eletronica/index.cfm?FuseAction=Artigo\&ID=1132\&Secao=INFORMAÇÃO\&Volume=1\&Numero $=2 \& A n o=2002$

CCopyright, 2002, RAE-eletrônica. Todos os direitos, inclusive de tradução, são reservados. É permitido citar parte de artigos sem autorização prévia desde que seja identificada a fonte. A reprodução total de artigos é proibida. Os artigos só devem ser usados para uso pessoal e nãocomercial. Em caso de dúvidas, consulte a redação: redacao@rae.com.br.

A RAE-eletrônica é a revista on-line da FGV-EAESP, totalmente aberta e criada com o objetivo de agilizar a veiculação de trabalhos inéditos. Lançada em janeiro de 2002, com perfil acadêmico, é dedicada a professores, pesquisadores e estudantes. Para mais informações consulte $o$ site www.rae.com.br/eletronica.

RAE-eletrônica

ISSN 1676-5648

(C)2002 Editora: Fundação Getulio Vargas - Escola de Administração de Empresas de São Paulo.

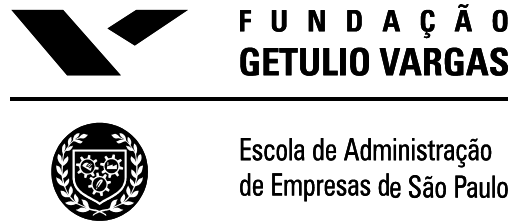




\title{
CAPITAL HUMANO E TI GERANDO VANTAGEM COMPETITIVA
}

\section{Marcelo Marques}

Administrador de Empresas, Especialização em Negócios pela FGV- EAESP, Pesquisador do mundo Linux e CEO da empresa 4Linux.

E-mail: mmarques@4linux.com.br

Endereço: Rua Teixeira da Silva, 660 - cj. 102

Interesses de Pesquisa: Marketing em Tecnologia da Informação, Tecnologia da Informação, Negócios em Tecnologia da Informação,

\section{Sylvio Lazzarini Neto}

Administrador de Empresas, Especialização em Negócios pela FGV-EAESP, Empresário do Setor de serviços e CEO da INTERMEZZO GOURMET S/A.

E-mail: sylazza@uol.com.br

Endereço: Rua Gal Mena Barreto, 793 - Jd. Paulista - São Paulo - SP, 01433-010

Interesses de Pesquisa: Estratégia e Marketing

\section{RESUMO}

Há fortes controvérsias quanto ao uso da tecnologia da informação e os resultados desses investimentos. Resulta ou não em vantagens competitivas? Como tornar convergente o treinamento e a valorização do capital humano com investimentos em tecnologia da informação? É possível gerar vantagens competitivas através da sincronia entre esses dois fatores? Fundamentado nos estudos de Michael E. Porter, este baseado nas idéias originais de Paul Milgrom e John Roberts (1990 e 1995), o presente trabalho propõe uma inovação em gestão administrativa com base nesse contexto, buscando mostrar que investimentos em TI e capital humano devem ser realizados conjuntamente, sob pena de ocorrer perda de eficiência no processo e, conseqüentemente, frustrações com os resultados obtidos.

\begin{abstract}
There are strong controversies in relation to using Information Technology and the results of these investments. Does it result or not in competitive advantages? How to turn convergent human capital training with investments in Information Technology? Is it possible to create competitive advantages through the synchrony between these both factors? Supported in Porter's studies, whose conception was originally based from Paul Milgrom and John Roberts ideas, this paper suggests an innovation in administrative management based on this context, looking to show that investments in IT and human capital should be done together, under penalty of occurring loss of efficiency in the process, and therefore frustration with the obtained results.
\end{abstract}

\section{PALAVRAS-CHAVE}

Capital humano, tecnologia da informação, vantagem competitiva, gestão do conhecimento e serviços.

\section{KEY WORDS}

Human capital, information technology, competitive advantage, knowledge management and services. 


\section{A REVOLUÇÃO DA TECNOLOGIA DA INFORMAÇÃO}

"Hoje em dia um carro Ford Taurus tem mais capacidade computacional do que os "Mainframes" multimilionários usados no programa espacial Apollo, mas custa bem menos. Em 1985, a Ford gastava US\$ 60.000 cada vez que um carro era destruido em testes de simulações de acidentes. Hoje, a mesma colisão pode ser simulada no computador por US\$100" ("The Economist" 2000)

O rápido e continuo declínio nos custos de informatização e os aumentos no poder e nas variedades de sistemas e computadores são endógenos e representam poderosa mudança no ambiente das organizações. Computadores estão tornando-se cada vez mais rápidos, pequenos, baratos e mais flexíveis, além de fácies de estarem interligados em rede. A redução dos preços dos equipamentos, no período compreendido entre 1990 e 2000 , no Brasil, (figura 1) ocorreu a uma taxa média de $15 \%$ ao ano, enquanto que a base instalada, representada por micros em uso, cresceu a uma taxa de $20 \%$ ao ano. Inúmeros especialistas prevêem que essa tendência deve continuar nos próximos anos. Isso explica o fato de diversas empresas estarem investindo e alocando crescentes somas de recursos visando readaptar e modernizar seus sistemas administrativos ao uso de TI. O aumento do número de usuários em relação ao total de funcionários nas empresas, na última década, foi de $18 \%$ ao ano, e deve também continuar crescendo nos próximos anos.

As empresas brasileiras estão cada vez mais investindo em informática. Isso pode ser constatado na relação dos gastos com informática em relação ao faturamento : em 1994 - 2,6\%; em 1998 - 3,4\% e em 2000-3,8\%, respectivamente, segundo dados da CIA/FGV-sp e do Gartner Group. O número é expressivo quando se compara o gasto médio das empresas européias, em particular, no mesmo período: $2,9 \% ; 4,0 \%$ e $5,0 \%$, respectivamente, também segundo a mesma fonte.

\begin{tabular}{|c|c|c|c|c|c|}
\hline \multicolumn{6}{|c|}{ Figura 1 - 10 Anos de Evolução do Uso e do Mercado } \\
\hline \multicolumn{3}{|c|}{ Mercado Brasileiro e Uso Corporativo } & \multicolumn{3}{|c|}{ Evolução Anual } \\
\hline Indices e Valores & 1990 & 2000 & 10 anos & 5 anos & 2000 \\
\hline Vendas no ano (milhões de micros) & 0,4 & 2,5 & $20,00 \%$ & $30,00 \%$ & $25,00 \%$ \\
\hline Base Instalada (micros em uso, milhões & 1,5 & 6,6 & $20,00 \%$ & $22,00 \%$ & $24,00 \%$ \\
\hline Preço do micro padrão (US 1000) & 5 & 1 & $-15,00 \%$ & $-16,00 \%$ & $-8,00 \%$ \\
\hline Custo Anual por teclado (US 1000) & 16 & 12 & $-3,00 \%$ & $-2,00 \%$ & $-15,00 \%$ \\
\hline Gastos Informática/Faturamento Liq & $1,40 \%$ & $3,80 \%$ & $10,00 \%$ & $8,00 \%$ & $12,00 \%$ \\
\hline Micros em Uso nas Empresas (mé & 60 & 810 & $30,00 \%$ & $26,00 \%$ & $21,00 \%$ \\
\hline Usuários Ativos nas Empresas (me & 150 & 955 & $20,00 \%$ & $20,00 \%$ & $17,00 \%$ \\
\hline Relação Usuário/Micro nas Empresas & 2,8 & 1,2 & $-8,00 \%$ & $-6,00 \%$ & $-4,00 \%$ \\
\hline Micros em Rede nas Empresas & $6 \%$ & $88 \%$ & $30,00 \%$ & $16,00 \%$ & $8,00 \%$ \\
\hline \% de usuário (usuários/funcionários) & $12 \%$ & $58 \%$ & $18,00 \%$ & $17,00 \%$ & $16,00 \%$ \\
\hline Relação Funcionários/Teclado & 17 & 3 & $-17,00 \%$ & $-15,00 \%$ & $-12,00 \%$ \\
\hline
\end{tabular}

\section{Fonte: CIA/FGV-SP}

Pesquisadores argumentam que uma das mais importantes razões para justificar os investimentos em TI é a melhoria da qualidade dos produtos, notabilizar os serviços para o consumidor, oportunidade e conveniência(Brynjolfsson and Hitt, 1995,2000). 
Entretanto, o que se observa é que estruturas organizacionais altamente computadorizadas são freqüentemente colocadas em xeque em razão da enorme quantidade de dados produzidos. A argumentação predominante é que esse efeito acaba produzindo ineficiências sistêmicas dentro da estrutura organizacional, perda de energia criativa, deficiência na coordenação de processos e métodos, além de estimular o aparecimento de focos internos de atritos. Essa situação acaba sendo agravada quando grupos internos demonstram desinteresse pela implantação de sistemas aprimorados de TI, principalmente quando estes envolvem operações em rede que sofisticam os controles e acabam salientando deficiências específicas, principalmente no gerenciamento das operações.

Esta é uma questão intrigante: cada vez mais as empresas estão investindo e usando TI, mas em muitos casos os resultados são falhos. Por que? Uma das explicações é que as empresas têm negligenciado investimentos em outras atividades as quais são necessárias para completar e reforçar os benefícios da TI, o que incompatibiliza a adoção de ações complementares como base de obtenção ou solidificação de vantagem competitiva sustentável (Porter, 1996; Milgrom \& Roberts, 1995).

Isso tem, entre outras, uma justificativa: a chamada "Lei de Moore" demonstra que a capacidade dos computadores dobra a cada 18 meses. Ao contrário, o homem encontra dificuldades enormes não só em saber lidar com as tecnologias existentes quanto, pior, acompanhar sua evolução.

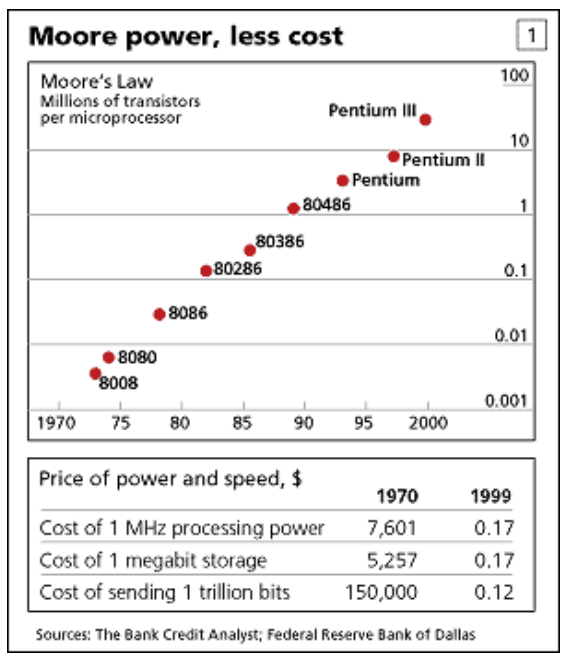




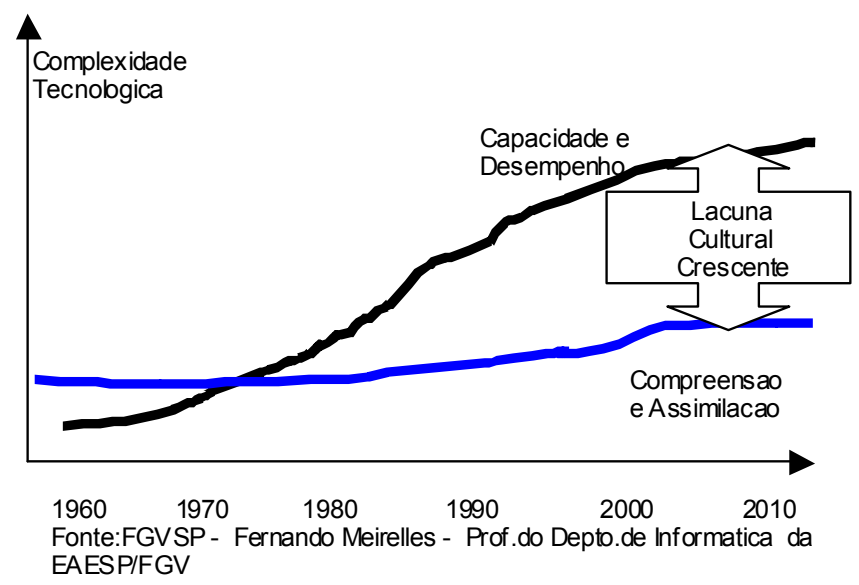

Nesse sentido, se um tipo de investimento for feito sem a adoção conjunta de um pacote de investimentos que se auto-reforça, organizações podem alcançar resultados apenas sub-ótimos. Assim, se investimentos em TI forem feitos sem investimentos em RH, corre-se o risco de não haver suficiente "base de competência" (conhecimentos, habilidades e aptidões individuais) na estrutura organizacional, de forma que se tenha condições de absorver o impacto que a implantação de novos sistemas, máquinas e outros dispositivos trarão no desempenho do RH como um todo. Entretanto, consideramos que quando se realizam tais investimentos a eficiência dos sistemas de informação aumenta porque alavanca fortemente o potencial da "base de competências" em todos os níveis hierárquicos. É formado, assim, um fluxo de complementaridade em duas vias: RH complementando TI; TI complementando RH.

O objetivo desta monografia, como então colocado, é expor a idéia de que vantagens competitivas sustentáveis só são geradas por investimentos conjuntos e consistentes em atividades complementares e que se auto-reforçam, tanto em TI quanto em RH.

\section{ESTRATÉGIAS COMPLEMENTARES E VANTAGENS COMPETITIVAS}

Entendemos que empresas que buscam sustentar vantagens competitivas no longo prazo devem considerar relevante investir em capital humano. O nosso entendimento, portanto, é que não há como dissociar o investimento nesse fator, nos diversos departamentos, com o investimento em TI, se o objetivo for aumentar a produtividade e ganhar poder de competência. Adicionalmente, devem também detectar os avanços tecnológicos e, por extensão, as ameaças que podem colocar em risco a sustentação do negócio e da rentabilidade no longo prazo. Como resultado, devem investir em larga escala na 
produção de um sistema integrado e eficiente de TI, conjuntamente com investimentos em capital humano, buscando obter, a um só tempo, a geração de eficiências e a dinamização do processo decisório.

Michael Porter em “What's strategy?”, argumenta que o avanço da TI e a integração dos mercados fizeram aumentar o ceticismo dos dirigentes em relação aos modelos de planejamento estratégico. A justificativa para esses novos dogmas consiste no fato de que concorrentes podem copiar rapidamente qualquer inovação, inibindo ou mesmo anulando as vantagens competitivas obtidas. $\mathrm{O}$ autor constata, ainda, que alguns dirigentes estão adotando posturas conservadoras, baseadas na adoção de táticas de negócios que tem tido o condão de tão somente resolver situações presentes, com raro interesse pela inovação e pela adoção de estratégias de longo prazo.

Neste artigo, Michael Porter defende que há meias verdades nessas crenças. Verdade, na medida em que barreiras competitivas têm sido derrubadas em razão da desregulamentação dos mercados e dos efeitos da globalização; verdade, na constatação de que empresas vêm desenvolvendo esforços para se tornarem mais ágeis e inteligentes; mas, inverdade quando essas mesmas empresas consideram a era da informação como uma ameaça, em razão da instalação de ambientes hiper competitivos.

No Brasil, pesquisas realizadas por Fernando Meirelles (2000) constataram que um grande número de dirigentes tem investido em TI com o objetivo de reduzir custos, principalmente de mão de obra. Essa decisão, segundo o nosso entendimento, é falha porque: (i) como veremos mais à frente, ganhos de produtividade são repassados para os clientes e (ii) TI requer empregados com um nível de habilidade pessoal superior. Esse contexto é agravado pelo fato desses dirigentes considerarem que a administração dos problemas do dia-a-dia é a maneira correta (e estratégica) para enfrentar o novo ambiente competitivo. Porter desconsidera parcialmente esse paradigma, anunciando que eficiência operacional é necessária, mas não suficiente: "A company can outperform rivals only if it can establish a difference that it can preserve. It must deliver greater value to customers or create comparable value at a lower cost, or do both. The arithmetic of superior profitability then follows: delivering greater value allows a company to charge higher average unit prices; greater efficiency results in lower average unit costs". (Porter, 1996, p.62)

Empresas eficientes, conhecem de sobejo esses enunciados. A questão crucial é que, sem aprofundar os investimentos em capital humano e TI, decisões estratégicas tomadas isoladamente não se constituem em alicerces para garantir a geração de lucros e o aumento de valor da empresa.

Um outro fator é que foco em eficiência operacional, com a finalidade de ganhar mercados, resulta em resposta imediata de outros competidores, iniciando-se um ciclo auto-destrutivo no setor. O que se constata atualmente, no Brasil, é que após uma década obtendo ganhos contínuos de produtividade, muitas empresas, antes operando com boa margem, estão agora sofrendo um processo de redução dos retornos, em razão, não só dos motivos já assinalados, como também em virtude da ação deletéria de empresas que utilizam expedientes de sonegação fiscal para obter vantagens sobre os concorrentes.

O ciclo nocivo, portanto, é assim estabelecido: ganhos de produtividade são imediatamente direcionados aos clientes em forma de redução nos preços, o que é copiado pelos concorrentes (alguns utilizando expedientes de evasão fiscal), fechando o ciclo, mas obrigando a empresa a reagir, iniciando outro ciclo para buscar maior nível de eficiência, etc. 
Essas situações são citadas por Porter (1996,p. 64): "Gradually, managers have let operational effectiveness supplant strategy. The result is zero-sum competition, static or declining prices, and pressures on costs that compromise companies ability to invest in the business for the long term".

Portanto, o alinhamento das decisões em razão do objetivo de lucrar deveria levar necessariamente os dirigentes das empresas a ajustar (fit) as competências e as estratégias em torno do objetivo principal de ganhar vantagens competitivas e sustentar lucros no longo prazo.

Além do correto posicionamento estratégico, os dirigentes devem combinar as estratégias escolhidas, viabilizando-as de forma a torna-las consistentes entre si. Esta é uma idéia original de Milgrom \& Roberts (1995) e que é também explorada por Porter (1996, p.70) : "Positioning choices determine not only which activities a company will perform and how it will configure individual activities but also how activities relate to one another. While operational effectiveness is about achieving excellence in individual activities, or functions, strategy is about combining activities “.

Esse ajuste ou combinação de estratégias é a ação que, em última instância, pode dificultar a entrada de competidores e impedir a ação dos chamados "imitadores". Combinar estratégias é diferente de adotálas, simplesmente. Quanto mais consistentes entre si, mais dificeis de serem imitadas. Por exemplo: combinando uma estratégia de informar rápida e adequadamente o cliente sobre determinado produto, com outra de serviço diferenciado e personalizado e com outra de produzir um produto de muitas e complexas especificações. TI resolve a primeira, RH faz a diferença na segunda e ambos fatores validam e reforçam a terceira. Não bastam funcionários gentis, amáveis e prontamente disponíveis. É preciso mais, nesse caso: (i) o funcionário que identifique o cliente, saiba das suas necessidades $\mathrm{e}$ conheça seus hábitos; (ii) TI disponível e RH que saiba como buscar essas informações e como também gerar informações preciosas para o sistema (o fluxo de duas vias) e (iii) feedback de informações para o setor de produção poder tornar as especificidades do produto cada vez mais originais e exclusivas.

As várias atividades realizadas, com o objetivo de obter lucro, se viabilizam na medida em que as pessoas na organização passem a reconhecê-las como estratégias. E isso só se consegue com muito treinamento e estimulo. A tecnologia da informação vem para reforçar esse posicionamento, dispondo de instrumentos que facilitam essa integração, como iremos debater nos modelos seguintes.

Uma primeira conclusão deve ser citada: se os empresários brasileiros adotarem TI somente com a intenção de reduzir custos não vão obter vantagens competitivas. Para obter tais vantagens é preciso buscar um complexo programa de investimentos onde TÍ é somente uma peça.

\section{RH E TI COMBINANDO ESTRATÉGIAS COMPLEMENTARES.}

\section{Como TI reforça investimentos em $\mathrm{RH}$}

A intensificação do uso de TI exige mudanças tanto de comportamento quanto na relação entre os diferentes setores e escalões dentro da estrutura organizacional o que, via de regra, impacta fortemente a gestão de recursos humanos como um todo.

Transformações econômicas e sociais ocorridas durante todo o século XX, assim como a globalização e os efeitos do uso intensivo da TI reforça a idéia de que é perceptiva a crescente convergência entre vantagem competitiva e mudança organizacional. Esta questão foi analisada por Vasconcelos e Cyrino (2000): "Diversas razões justificam a convergência entre as duas correntes (vantagem competitiva e 
mudança organizacional). Primeiramente, a evolução dos ambientes organizacionais, cada vez mais marcados pela evolução tecnológica, pela interconexão entre grandes redes de organizações e pela integração dos mercados mundiais. Altos níveis de incerteza e ambigüidade ambiental contribuem fortemente para que a mudança organizacional seja vista não como um evento raro, mas como uma ocorrência cada vez mais freqüente nas organizações. A importância da mudança organizacional é, assim, posta em evidência pela percepção generalizada de que a mudança é essencialmente inevitável.

Daí surge uma forte motivação para compreender e influenciar os processos de mudança organizacional, estabelecendo uma interface entre a estratégia como fenômeno intencional e o comportamento organizacional como fenômeno emergente".

Bresnahan, Brynjolfsson e Hitt (2000) compartilham com este pensamento, ressaltando a correlação entre o grau de habilidade e eficiência dos empregados, vis-à-vis com as mudanças organizacionais em face de um ambiente permeado de novas tecnologias e TI.

Por melhor que seja a interatividade, na fase posterior à implantação de sistemas avançados, começam a surgir problemas de várias ordens e magnitudes. Emerge, a partir daí, uma enorme controvérsia de que os investimentos em TI são onerosos e de baixo retorno, estabelecendo-se, também a partir desse conceito, uma certa confusão quando à viabilidade de investir em tecnologia e no treinamento dos recursos humanos, simultaneamente.

A invenção de novos produtos e a adaptação para um novo modelo organizacional, per si, requer maiores níveis de habilidade e percepção individuais, integrados a uma maior flexibilidade e autonomia da gestão de RH do que nos sistemas tradicionais, onde o processo produtivo é determinado e inclui arbítrios extemporâneos da alta direção, muitas vezes ou na maioria das vezes, dissociados do processo. Bartel and Lichtenberg (1987\} sugerem que habilidade e percepção individuais podem ser importantes na adaptação de mudanças gerais, notavelmente quando da adoção de novas tecnologias.

TI reforça RH, portanto, na medida em que disponibiliza quantidades crescentes de informações e possibilita que a coordenação entre os vários setores da organização seja realizada com maior facilidade.

Thomas Gilbert (1992) argumenta que informações inadequadas são a principal causa de mais da metade dos problemas de desempenho humano. Primeiro, porque os empregados precisam de informações que lhes dêem um norte, no sentido de compreender qual a missão da empresa, sua estratégia e o que constitui o bom desempenho na avaliação da alta direção. Segundo, porque precisam de medidas, metas e objetivos que possam utilizar para monitorar e obter feedback sobre o desempenho geral. Não basta examinar somente as ferramentas, as técnicas, os métodos e as tecnologias que as pessoas devem usar para executar o trabalho. É preciso treinamento e aprendizado constante. A figura 1 mostra as etapas que, segundo Gilbert (1992), devem ser seguidas para se criar um ambiente de trabalho de forma que o desempenho humano seja melhorado. 


\section{Figura 2}

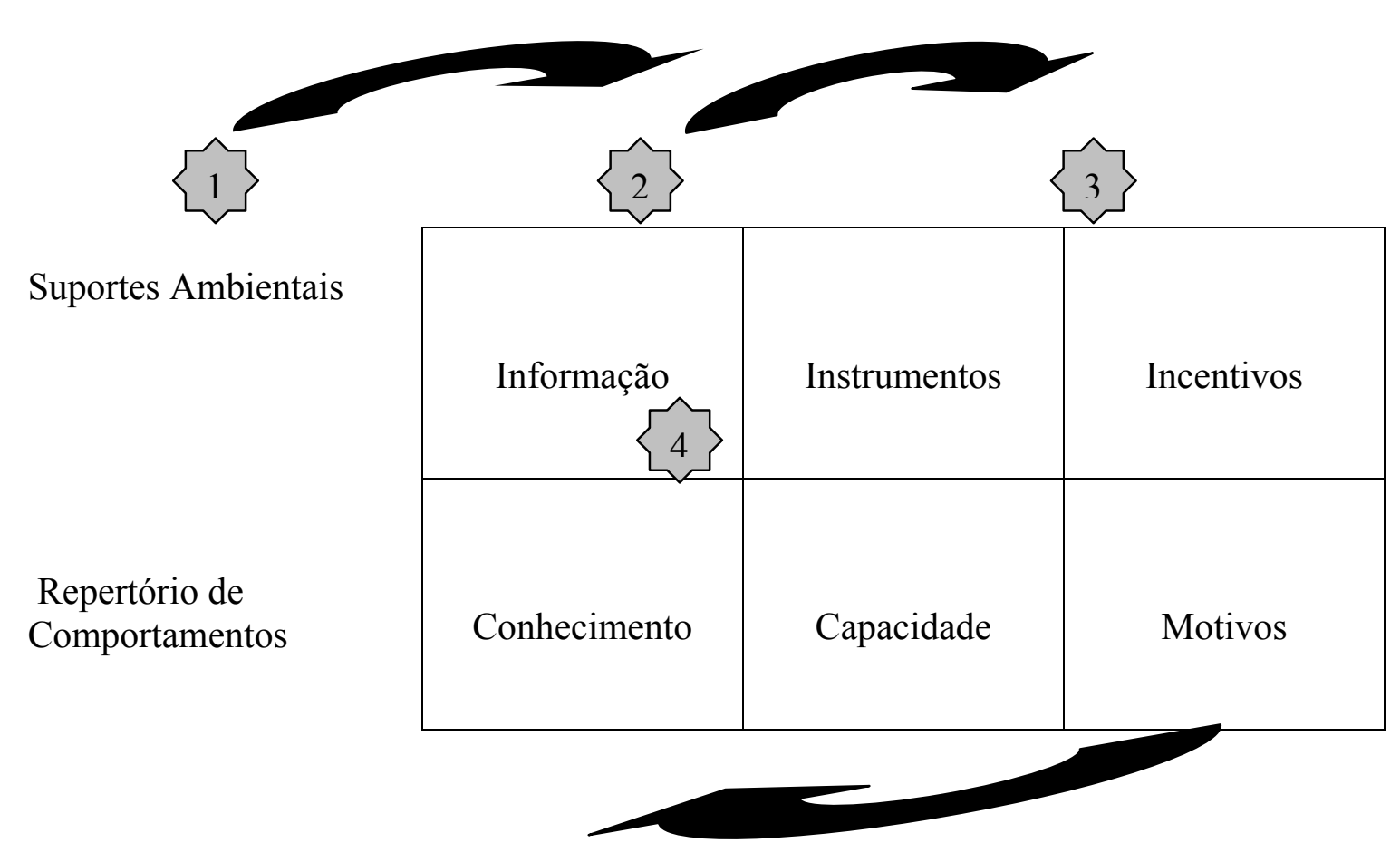

Fonte: Adaptado de Thomas Gilbert (1992) 


\section{Resumindo a Interatividade TI - RH}

* Aumento da intensidade de comunicação organizacional;

* Melhoria da coordenação de atividades por meio de interfaces padronizadas de trocas de informação e feedback;

* Intercâmbio de idéias entre especialistas dentro da empresa;

\section{Como RH Reforça Investimentos em TI}

$O$ objetivo fundamental da gestão de recursos humanos numa organização é a identificação e desenvolvimento das competências que irão sustentar a intenção estratégica da organização. A área de recursos humanos precisa atuar como um parceiro estratégico. A incapacidade de estabelecer esta parceria e de evidenciar a importância da função de RH para a elaboração e implementação de estratégias competitivas é o que provoca, na maioria das vezes, o papel relativamente secundário alocado para o RH em muitas empresas (Brandão, 2001).

É interessante essa questão: na medida em que equipes de trabalho são treinadas, buscando tornarem-se cada vez mais produtivas, facilita-se a forma e a oportunidade de envolve-las nas diversas estratégias escolhidas pela empresa, visando obter vantagens competitivas. Cada vez que equipes são treinadas e funcionários são escolhidos também pelo critério de relacionamento (pessoas que saibam trabalhar bem com as outras), ampliam-se as possibilidades de um aprendizado constante e uniforme de como operar complexos sistemas em rede.

Equipes treinadas desenvolvem uma forte intuição perceptiva e passam a valorizar os investimentos em TI. Fecha-se, assim, um ciclo que pode ser configurado pela seguinte ilustração:

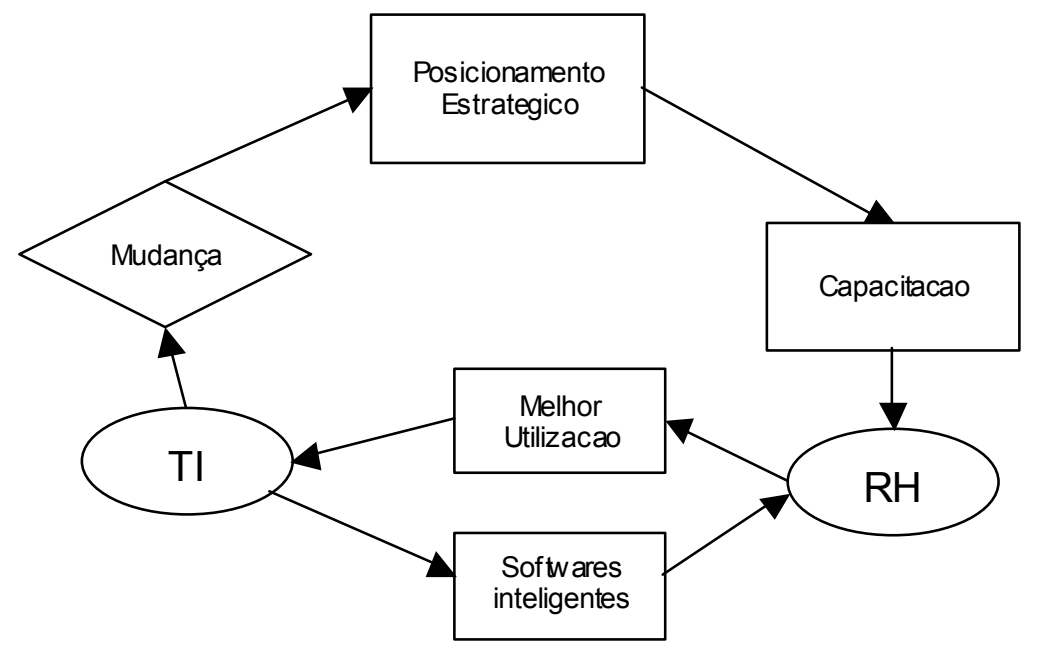




\section{Resumindo a Interatividade RH - TI:}

* Uso efetivo das estruturas de comunicação interna. Novas estruturas podem ser instituídas, mas é fundamental que as pessoas tenham capacitações para usá-las;

* Maior disponibilidade de conhecimento que pode ser difundido dentro da empresa por meio de sistemas de informação;

* Uso criativo de sistemas de informação. Por exemplo: agregar informação sobre consumidores, novos canais de vendas, etc, o que significa ir além da TI como simples redutora de custos.

A conexão entre os dois fatores não pode ficar restrita à área responsável pela gestão de RH. É preciso que haja, dentro da organização, um departamento fazendo a interface entre os vários setores envolvidos na execução do planejamento estratégico com base instalada de TI, inclusive com responsabilidade direta no treinamento e desenvolvimento dos usuários do sistema, checagem das informações, interpretação dos dados gerados e interposição de decisões estratégicas, quando necessárias.

Imperioso, portanto, concluir que estratégias adotadas, sem combinação com os fatores expostos estão virtualmente fadadas ao insucesso, principalmente porque a revolução gerada pela TI está apenas no começo e, o que é moderno hoje, será obsoleto em poucos anos ou até meses, caducando toda a estrutura organizacional e fazendo cair por terra todos os investimentos realizados em TI. Isso deve ter um sentido extremamente preocupante para os empresários brasileiros, não só em razão das dificuldades ainda encontradas no acesso permanente com novas tecnologias, como, principalmente, em razão da possibilidade de novos entrantes, principalmente estrangeiros, prontos para operar dentro do desenho operacional que discorremos.

\section{ESTUDOS DE CASOS:}

\section{1 - Editora Gráficos BURTI}

Fundada em 1977, a Editora Gráficos Burti percebeu de forma inovadora e avançada que a tecnologia poderia trazer enormes vantagens competitivas ao seu negócio. Sua grande cartada foi sair na frente dos concorrentes, treinando, não só sua equipe, mas também seus clientes, de forma a poder controlar todo a interação dos processos, através da tecnologia. A empresa foi pioneira de um sistema de Desktop Publishing. Em 1995 a empresa possuía uma carteira de cliente em torno de 100 agências. Naquele ano, seu faturamento foi de US\$ 80 milhões. Em 1994 faturou US\$ 60 milhões e, nos anos anteriores, o crescimento anual e real do faturamento foi da ordem de $20 \%$.

Ela inovou a forma tradicional de se fazer negócios. No método tradicional, o Diretor de Arte de uma agência só dá o aceite do resultado do trabalho da gráfica, após várias trocas de jargões, idas e vindas de "motoboys", troca de arquivos, etc. A Burti percebeu que se pudesse eliminar toda essa "burocracia", fazendo com que o feedback empresa-cliente fosse eletrônico, com uma equipe treinada dentro da Burti e outra equipe treinada dentro do cliente e agências, a eficiência na gestão do processo se elevaria e estaria completa. Ressalte-se, igualmente, que, no método tradicional, o processo de criação envolve um complicado jogo de comunicação e uma exasperante logística de transporte de fotos, esboços, provas e cromos, da agência para a gráfica e vice-versa.

A Burti acabou investindo em tecnologia e treinamento cinco vezes mais do previsto, em toda a cadeia, mas o resultado valeu a pena. 
Ela interligou os clientes em um sistema de comunicação próprio, mas com um custo/benefício muito superior ao oferecido na época. Colocou um servidor Challenger, da Silicon Graphics, com 160 GB de disco rígido e 2 GB de memória RAM de ponta dentro da Burti e, para as agências, ofereceu estações de trabalho Indy, também da Silicon Graphics, com 1 gigabyte de disco rígido e 32 megabytes de memória RAM, equipadas com câmara, microfone e software InterPerson para videoconferência.

Durante o primeiro ano, o sistema atingiu treze agências de publicidade com os nomes mais importantes, e também dois grandes jornais do País.

Não se estabelece confusão nas cores para a elaboração do trabalho, pois todos profissionais envolvidos, através da videoconferência, utilizando o mesmo software e fontes, estão vendo o mesmo conteúdo eletrônico. Uma única alteração realizada de um lado reflete em todo o sistema.

\section{2 - Intermezzo Comercial Gourmet - Gerenciando Lojas com TI}

Um outro caso é a Intermezzo - Comercial Gourmet. Essa empresa fornece carnes especiais para restaurantes e hotéis, mas também atende consumidores, em parceria com uma empresa especializada em atendimento e entregas, via "cal center" ou Internet, através de site próprio. A empresa, neste momento, está iniciando o projeto de construção de uma cadeia de lojas de varejo e também de fast food. O objetivo da empresa será buscar atender consumidores que demandam produtos diferenciados.

A loja oferecerá uma gama de serviços altamente diferenciados aos seus clientes, com uma combinação de produtos de reconhecida qualidade.

Para absorver o pacote tecnológico, os funcionários são submetidos a intenso treinamento e aprendizado de como utilizar softwares avançados, operando em rede. O sistema das atividades abaixo demonstrado, desenvolvido a partir de um modelo de Michael Porter (1996), oferece uma boa visão de como o posicionamento estratégico da empresa poderá trazer-lhe vantagens competitivas. Com fundo preto, identifica-se os posicionamentos básicos e sua relação às inúmeras estratégias complementares que, no conjunto, conferirão vantagem competitiva.

A Empresa planeja investir cerca de $10 \%$ do seu faturamento em TI e treinamento conjunto de RH, nos próximos anos.

Pretende, também, estender esse treinamento para os funcionários dos fornecedores que lhe são estratégicos, como os produtores de novilhos especiais e outras commodities, de forma que estes possam estar interligados aos sistemas de atendimento, respondendo pontualmente às eventuais reclamações de consumidores e clientes. 


\section{SISTEMA DAS ATIVIDADES}

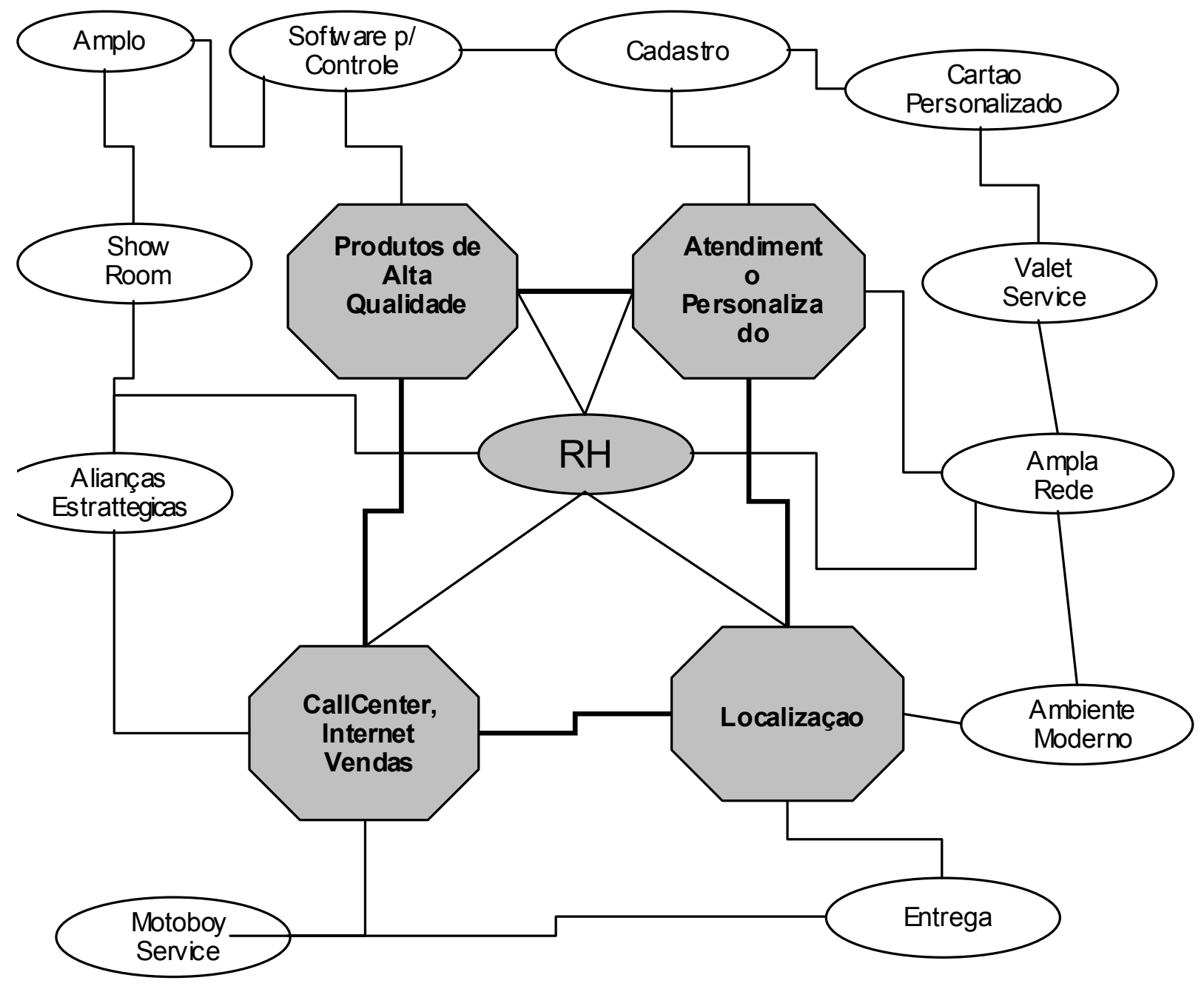

Esse sistema foi adaptado do modelo de Porter (1996,p.71) - Mapping Activity Systems

A cadeia de informações de todo o sistema é demonstrada no modelo abaixo, no qual o feedback é realizado de forma permanente e consistente. 


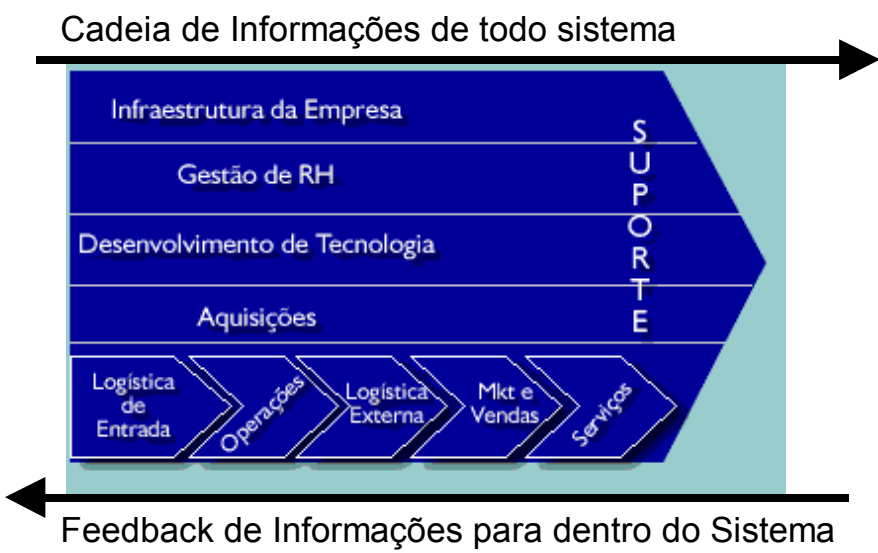

No contexto do atendimento ao cliente - razão da integração entre recursos humanos e TI - é priorizada a utilização de um sistema personalizado, de forma que, ao chegar na loja, o cliente é imediatamente identificado. Esse procedimento facilita a abordagem dos funcionários envolvidos no atendimento. Igualmente são disponibilizados inúmeros dispositivos de "show room", de forma também que o cliente possa efetuar suas consultas e da maneira que melhor lhe convier. Exemplo: um show room de vinhos, que contem dados preciosos para a decisão do quê e quanto comprar:

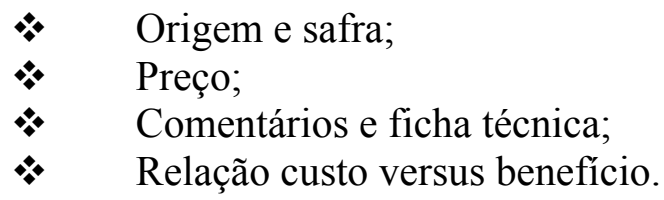

No plano externo, o sistema é interligado a um eficiente processo de gestão e controle de qualidade, vendas, estoques e rapidez na entrega, como segue:

- Fornecedores conectados, via on line, para gestão de vendas, estoques e serviços de informações ao cliente;

- Rapidez na entrega do produto adquirido, se o serviço for terceirizado;

\section{CONCLUSÃO}

Entende-se que a inovação em administrar esse processo está justamente em ajustar o uso permanente e eficiente da TI com uma gestão de recursos humanos em um fluxo de duas vias (TI reforça RH; RH reforça TI), e que priorize: (i) quais as informações devem estar disponibilizadas para os funcionários enfrentarem diferentes situações no ambiente interno e (ii) quais informações estes funcionários devem gerar para o surgimento de novos conceitos ou para aferição da eficácia nas operações, ajustes e controle dos resultados obtidos em confronto com os esperados ou previstos.

A inovação em administração, portanto, está em conciliar treinamento de recursos humanos e investimentos em TI; saber como trabalhar com a informação juntos dos funcionários e, finalmente, em um modelo que aceite entrada de informações também pela "saída". A menos complexa tarefa seria o desenho desse sistema. Hoje, graças aos padrões de TCP/IP (a linguagem da internet), é possível 
conceber sistemas que podem se comunicar uns com os outros. A linguagem XML (eXtended Markup Language) é um avanço nessa linha. Ela permite que, por exemplo, uma nota físcal de qualquer fornecedor entre eletronicamente dentro de um sistema sem que os dois fossem desenvolvidos para se comunicar entre si. Ela classifica os campos da nota de forma padrão, através do campo: "número de série"... Dessa forma, é possível estabelecer um sistema que faça com que os fornecedores interajam mais fácil com seus clientes em uma cadeia de valor envolvendo controle de estoque, por exemplo. E nesse mesmo controle de estoque é possível que em um determinado supermercado, por exemplo, quando um cliente devolve um peixe supostamente estragado, acione imediatamente o fornecedor, de forma que este, on-line, conheça o problema e já providencie uma análise na remessa do produto reclamado e sane a falha na origem.

\section{Contribuição do trabalho.}

Propor um modelo que convirja o treinamento dos recursos humanos sincronizado com o uso da TI, com vistas à obtenção de vantagens competitivas duradouras.

Propor que as empresas interessadas em desenvolver sistemas avançados operando em rede, disponham de um eficiente programa de treinamento, para aprendizado e desenvolvimento, nos vários níveis da organização.

Propor a criação e aperfeiçoamento de múltiplos links entre áreas funcionais da empresa. Essas áreas devem executar o discutido "pacote" de múltiplas estratégias e que são consistentes entre si, como visto, e que enfatizem:

Recrutamento e Seleção

Treinamento e Desenvolvimento de RH

Análises de sistemas e softwares

Desenvolvimento de Novos Processos e Métodos

\section{Recomendações finais aos empresários brasileiros:}

É recomendável que a alta administração confira poderes especiais a um departamento de "Conhecimento e Gestão Tecnológica" (Chief Knowledge Office), no sentido de que este possa incentivar o engajamento de toda a estrutura organizacional no processo de TI, bem a evolução dos sistemas implantados. É comum perceber que empresas deixam de lado altos investimentos em TI, porque são criadas "necessidades" paralelas - e muitas vezes desnecessárias - e que acabam comprometendo o sucesso da implantação de sistemas especializados.

Essa é uma questão fundamental e deve ser entendida, pela alta administração como essencial no processo da administração estratégica. Impõe, portanto, as seguintes definições:

Interação entre todos os setores da organização;

Ampla participação da alta administração no processo; 
Assessoria externa em TI integrada no processo de gestão;

Reconhecimento das informações geradas e recebidas;

Acesso fácil a qualquer tipo de informação não estratégica;

Transferência rápida de conhecimento de um funcionário para outro.

\section{Em resumo:}

Investir em Capital Humano na mesma proporção do que em TI;

Investir em quem apóia as mudanças;

Redução de custo deve ser conseqüência e não meio;

Focar a gestão do conhecimento;

\section{Artigo recebido em 06.05.2001. Aprovado em 10.05.2002.}

\section{BIBLIOGRAFIA}

BRESNAHAN, TIMOTHY F., BRYNJOLFSSON, ERIK, HITT, LORIN M. - Information Technology, Workplace Organization and the Demand for Skilled Labor: Firm-Level Evidence.

DRUCKER, PETER F. - A Organização do Futuro - Futura - Pg: 15-24; 195-206; 219-232;

GILBERT, T. - HUMAN COMPETENCE (1992)

MILGROM, P.; ROBERTS J. - The Economics of Modern Manufacturing: Technology, Strategy, and Organizations - American Economic Review 80 (1990): 511-528;

MILGROM, P.; ROBERTS J. - Complementaries and Fit: Strategy, Structure, and Organizational Changes in Manufacturing - Journal of Accounting and Economics, vol.19 (march-May, 1995): 179208;

PORTER, MICHAEL E. - What is Strategy - Harward Business Review - November-December, 1996

PORTER, MICHAEL E. - Competição Estratégias Competitivas Essenciais - Campus - Seguda Edição Pg 46-106

REVISTA EXAME - Edição 727- 15/Novembro/2000 - Peter Drucker, com um pé atrás - Pg: 120-131

REVISTA THE ECONOMIST - 23/Setembro/2000 - Survey: The New Economy - Encarte pg: 67

VASCONCELOS, FLÁVIO C. E CYRINO, ALVARO B. - Vantagem Competitiva: os modelos teóricos atuais e a convergência entre estratégia e teoria organizacional. 